\title{
Fluorescence of Selected Polymer Banknotes
}

\author{
Michaela Mikulicova, Ondrej Zimek \& Vojtech Kresalek
}
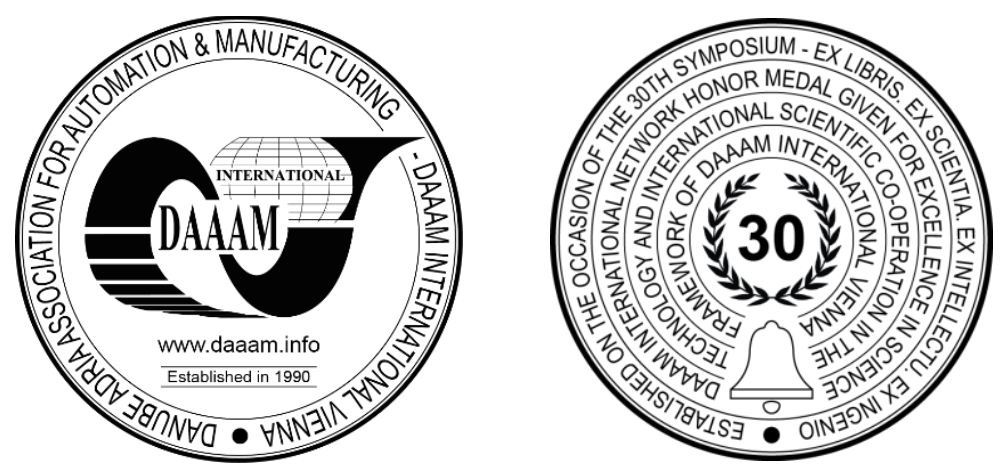

This Publication has to be referred as: Mikulicova, M[ichaela]; Zimek, O[ndrej] \& Kresalek, V[ojtech] (2019). Fluorescence of Selected Polymer Banknotes, Proceedings of the 30th DAAAM International Symposium, pp.0746-0752, B. Katalinic (Ed.), Published by DAAAM International, ISBN 978-3-902734-22-8, ISSN 1726-9679, Vienna, Austria DOI: $10.2507 / 30$ th.daaam.proceedings.102

\begin{abstract}
In this paper, selected polymer banknotes from Great Britain, Hong Kong, Mexico and Russia are investigated. First, a UV lamp is used to visualise fluorescent radiation of the banknotes, and the banknotes are photographed. Subsequently, selected parts of the banknotes are further analysed by steady-state fluorescence spectroscopy. For each banknote, the part containing the fluorescent dye is compared with the part without the security feature. The results demonstrate the properties of the fluorescent dyes, which are used as a security feature for polymer banknotes. These properties can be further used to detect counterfeits.
\end{abstract}

Keywords: polymer banknote; fluorescent dye; fluorescence spectroscopy; UV lamp

\section{Introduction}

Banknotes are a standard part of the physical form of currencies around the world. The first banknotes appeared in China, in Europe, the first paper money began to be used in the second half of the 17th century in Sweden [1]. The reason for the creation of banknotes could be the lack of precious metals for the production of coins, but also the problematic management of larger volumes of money. Similar to coins, banknotes have undergone a long evolution. The main reason for the research and development of new forms of banknotes (shapes, materials, features on banknotes) was mainly to improve banknotes to prevent their forgery [2]. Especially in the second half of the 20th century, the possibilities of reproduction were greatly simplified, and the production of simple counterfeits became very easy; [3] speaks of "the democratisation of these crimes."

Counterfeiting of classic paper banknotes is not quite easy as no commonly available paper is used for their production [4]. At first glance and during a quick exchange of money, a counterfeit printed on a quality printer may be indistinguishable from the original banknote [5], [6], [7], [8]. Although with the abolition of the so-called gold standard and with the spread of modern payment technologies (payment cards, internet banking, cryptocurrencies) the importance of physical money is declining, they are still in some way irreplaceable [2].

Polymer banknotes are currently the last stage in the development of physical money. A special polymer substrate made of Guardian TM biaxially oriented propylene is used to produce the polymer banknotes [2], [9]. The banknote consists of three layers: a ClarityTM C base foil, an opaque layer for ink adhesion during printing, and printed or embedded security features [10]. Current polymer banknotes contain many modern security features that make counterfeiters much more difficult and expensive. Polymer banknotes can have three levels of security features. Primary security features 
(for example intaglio printing, metallic tapes, a polymer window) are easily recognisable by the public. Secondary security features (for example magnetic colours or fluorescent colours visible under UV light) require special devices for detection. Tertiary security features are detectable primarily by the banknote issuer [2].

The disadvantage of polymer banknotes is their purchase price, which is higher than paper banknotes. However, due to their longer life, their production is ultimately cheaper than the production of conventional banknotes. Their advantage is the limited possibility of counterfeiting [2]. It is easy to detect lower-quality counterfeits because the polymer window and optically variable security features cannot be easily imitated using available digital devices. Moreover, the polymer banknotes are difficult to destroy - damaging or tearing is more complicated than in the case of paper banknotes [2]. Besides, polymer banknotes are intact against water or other common liquid and, due to their less rugged surface, they are less stained and less suitable for carrying microorganisms [11].

Microscopy and non-destructive methods such as Raman spectroscopy, FT-IR and X-ray fluorescence are commonly used to identify counterfeit banknotes [5], [12], [13], [14]. Destructive methods, such as gas chromatography and mass spectrometry, can also be used [6], [11]. In particular, the characteristics of the individual features of the banknotes and their possible applicability for the detection of counterfeits are examined for example in: [15] for historical banknotes, [5], [6], [7], [8], [12], [16] for paper banknotes and [13], [17] for polymer banknotes. These methods can also be used for the analysis of printing on polymer [18].
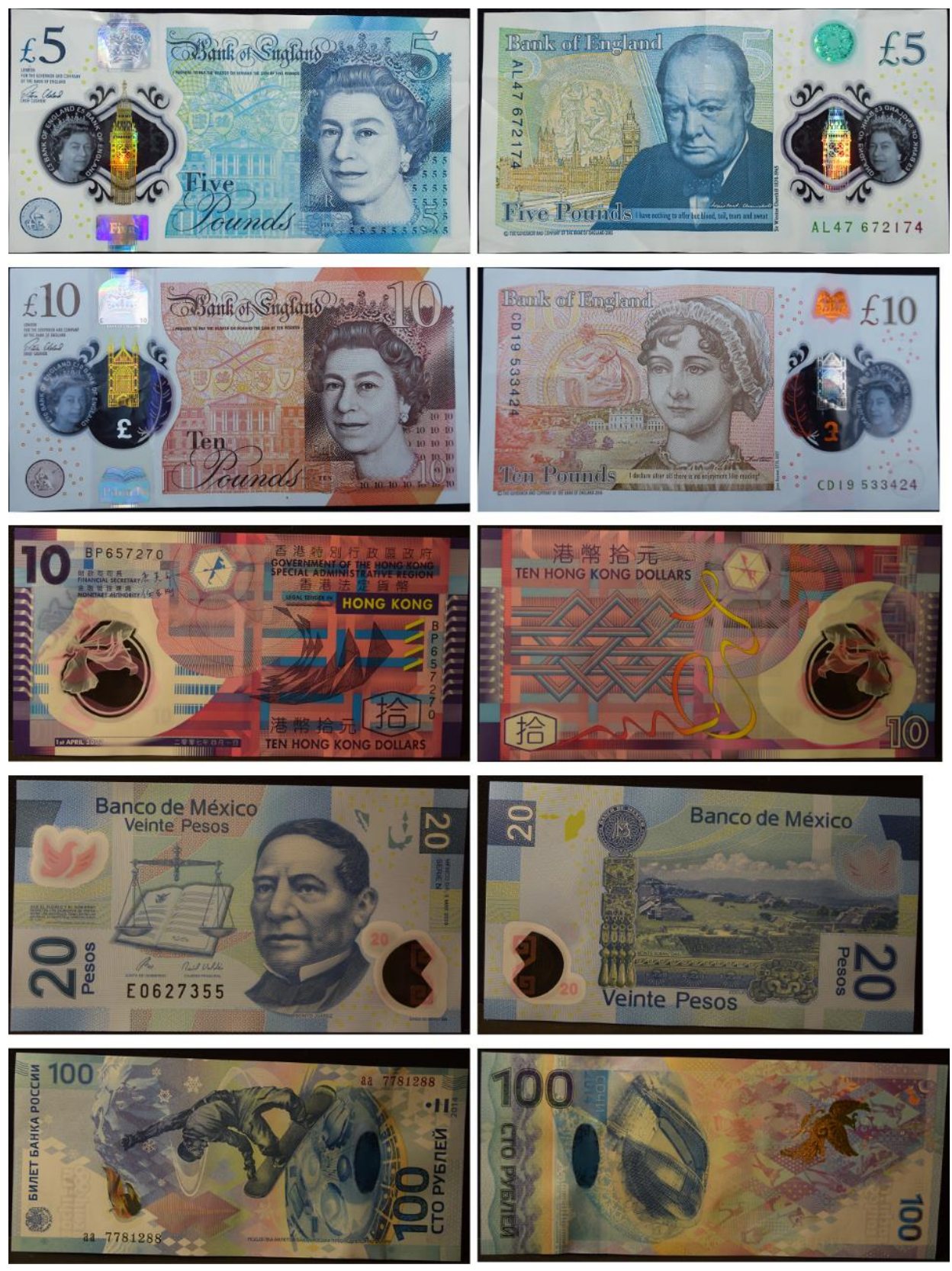

Fig. 1. The polymer banknotes of Great Britain ( $£ 10$ and $£ 5$ ), Hong Kong ( $\$ 10)$, Mexico (20 pesos) and Russia (100 rubles); the face side is on the left; the reverse side is on the right 
In this paper, a UV lamp is used to visualise the fluorescence of the polymer banknotes. Subsequently, selected parts of the banknotes are further examined by steady-state fluorescence spectroscopy. While the use of a UV lamp is common practice for detection of counterfeit polymer banknotes, the use of fluorescence spectroscopy for this purpose has been studied only a little although this method is simple, quick, contactless and has a negligible influence on the investigated sample. The purpose of this paper is to demonstrate the ability of steady-state fluorescence spectroscopy to analyse fluorescence properties of fluorescent dyes, which are used as security features for polymer banknotes.

\section{Instrumentation and Samples}

UV analysis lamp Krüss UV240 was used to visualise the fluorescence of the banknotes. This UV lamp has two wavelengths: $254 \mathrm{~nm}$ and $366 \mathrm{~nm}$. Light with a wavelength of $366 \mathrm{~nm}$ was chosen as more suitable for banknote analysis. All banknotes were photographed in daylight and under the UV lamp using a Nikon D7100 camera.

Then, selected parts of the banknotes were further analysed by steady-state fluorescence spectroscopy. Emission spectra were obtained by an ISS PC1 spectrofluorometer which is equipped with $300 \mathrm{~W}$ high-pressure xenon arc lamp (a source of excitation light) and photomultiplier in photon counting mode (a highly sensitive detector). To measure in a horizontal plane, an optical fibre was used. An excitation wavelength was set to $366 \mathrm{~nm}$. The emission spectra were measured in the range from 390 to $680 \mathrm{~nm}$.

The polymer banknotes of Great Britain, Hong Kong, Mexico and Russia were selected for analysis. Specifically, the banknotes, which had the value of $£ 10$ and $£ 5$ (British banknotes), \$ 10 (Hong Kong banknote), 20 pesos (Mexican banknote) and 100 rubles (Russian banknote), were examined.

\section{Results}

The aim of the experiment was to investigate fluorescent dyes, which are used as security features for polymer banknotes, by steady-state fluorescence spectroscopy. For this purpose, the emission spectra of selected polymer banknotes (Fig. 1) were measured and the fluorescence properties of the used fluorescent dyes were monitored.
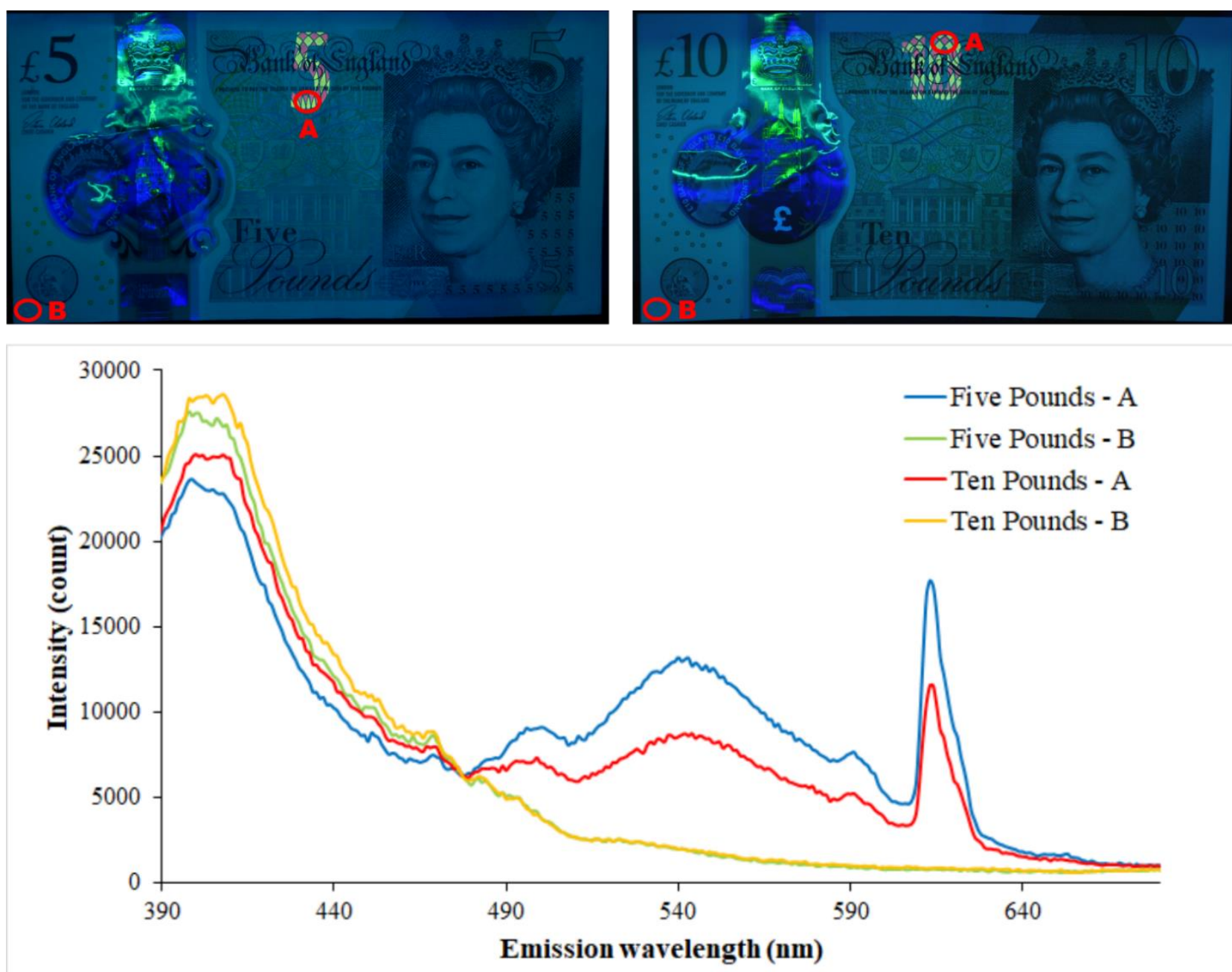

Fig. 2. Photographs of British banknotes ( $£ 5$ and $£ 10$ ) under a UV lamp and emission spectrum of these banknotes 
Fig. 2 shows photographs of British banknotes ( $£ 5$ and $£ 10$ ) under the UV lamp and subsequently the emission spectra of these banknotes. As can be seen, the fluorescent security features are located on the face side of these banknotes. Specifically, it is a number, which expresses the value of banknotes. This number consists of yellow-green and red fluorescent dyes for both banknotes.

Two areas were examined for both British banknotes. The area containing the fluorescent dye was marked with A; the area without the dye was marked with B. All measured areas have considerably intense fluorescence around the peak at $410 \mathrm{~nm}$, which corresponds to dark blue colour. This region of fluorescence, which is caused by optically brightening agents added to the banknote material, occurs at a similar intensity in all investigated banknotes. Area B shows no fluorescence other than this. Area A has peaks at $500 \mathrm{~nm}, 540 \mathrm{~nm}, 590 \mathrm{~nm}$ and $620 \mathrm{~nm}$, corresponding to colours green, yellow-green, yellow and red, whereas the peaks corresponding to yellow-green $(540 \mathrm{~nm})$ and red $(620 \mathrm{~nm})$ are the most significant. These findings are in agreement with the results obtained by the UV lamp where yellow-green and red colour features are visible. The lower fluorescence intensity of the $£ 10$ banknote could be caused by impurities on the measured sample. Nevertheless, the shape of the spectrum is similar for both banknotes.
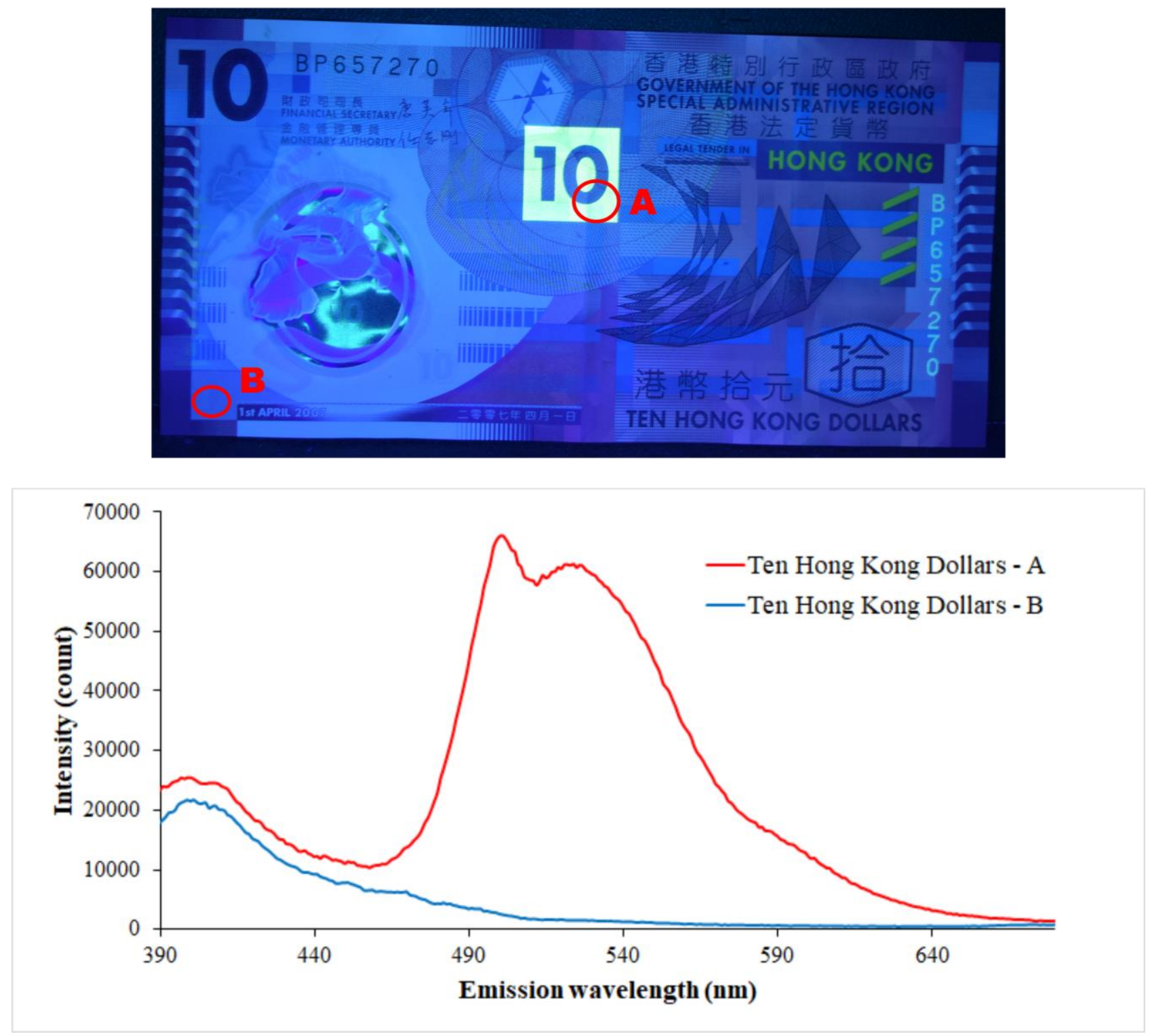

Fig. 3. Photograph of Hong Kong banknote under a UV lamp and emission spectrum of this banknote

Fig. 3 presents a photograph of Hong Kong banknote (\$ 10) under the UV lamp and the emission spectra of this banknote. As can be seen, the fluorescent security feature, a fluorescent green square, is located on the face side of this banknote.

Two areas were measured for the banknote. The area containing the fluorescent dye was marked with A; the area without the dye was marked with B. Both measured areas have fluorescence around the peak at $410 \mathrm{~nm}$, as described above for British banknotes. Area B has no other fluorescence. Area A has a narrow peak at $500 \mathrm{~nm}$ corresponding to green colour and a broader peak around $525 \mathrm{~nm}$ corresponding to light green. This means that the used fluorescent dye 
consists of pigments of these two colours. These pigments create the resulting colour of the security feature visible under the UV lamp.

A photograph of Mexican banknote (20 pesos) under the UV lamp and the emission spectra of this banknote are illustrated in Fig. 4. It is worthwhile to note that this banknote, unlike the other examined banknotes, has fluorescent elements on the reverse side. As can be seen, all fluorescent features have yellow-green colour of varying intensity.

Three areas were analysed for Mexican banknote. The area containing the high-intensity fluorescent dye was marked with A; the area containing the low-intensity fluorescent dye was marked with B; the area without the dye was marked with C. All measured areas have fluorescence around the peak at $410 \mathrm{~nm}$, as described for previous banknotes. Area C shows no fluorescence other than this. Both A and B areas have two fluorescence peaks at $525 \mathrm{~nm}$ and $560 \mathrm{~nm}$. These peaks correspond to darker and lighter yellow-green colour. The figure reveals the difference in fluorescence intensity - area A has a higher fluorescence intensity than area B, which corresponds to the results obtained by the UV lamp. However, it can be seen that the same fluorescent dye is used for both areas because the shape of their spectra is similar.
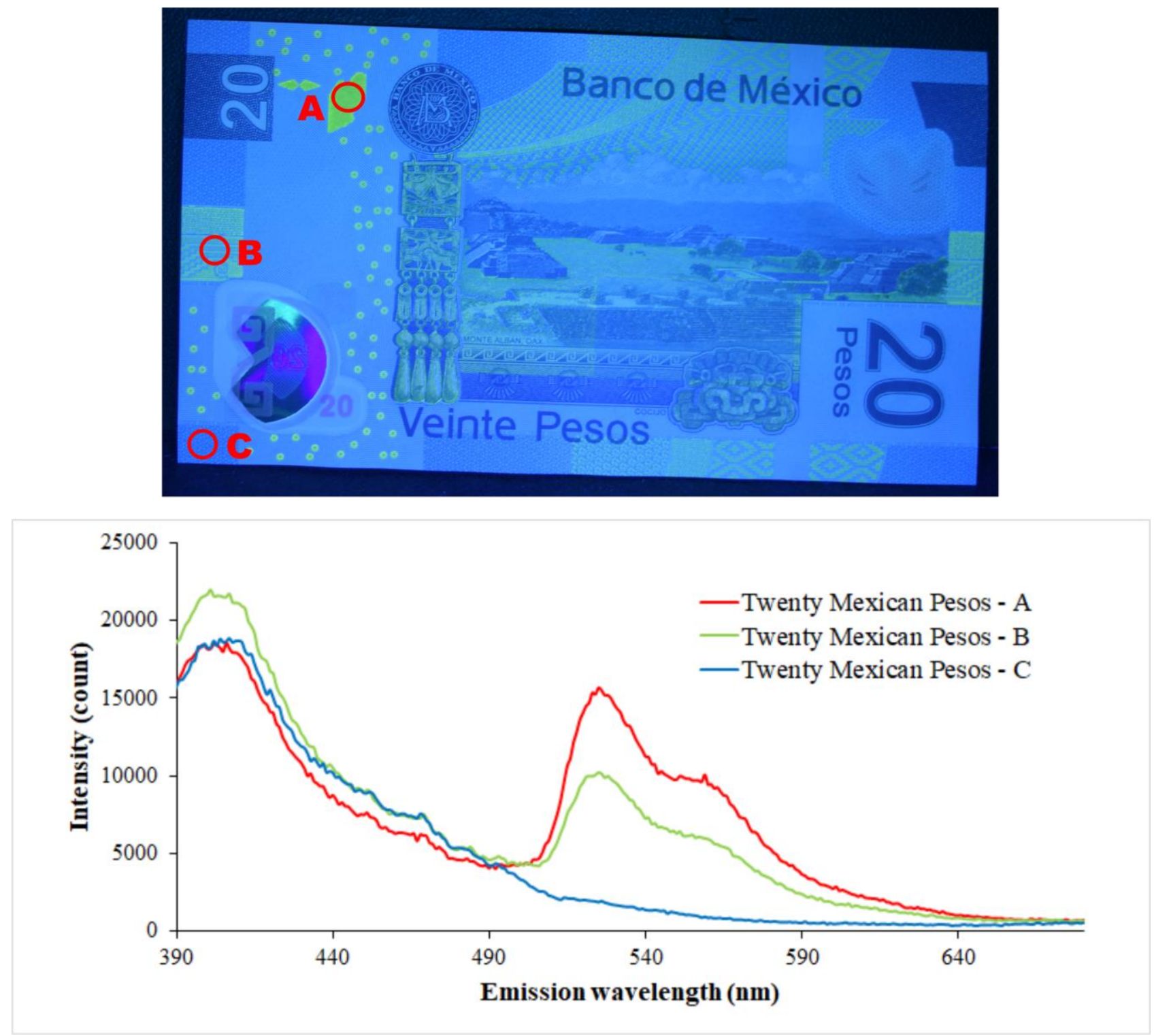

Fig. 4. Photograph of Mexican banknote under a UV lamp and emission spectrum of this banknote

Fig. 5 shows a photograph of Russian banknote (100 rubles) under the UV lamp and the emission spectra of this banknote. As can be seen, the fluorescent security features are located on the face side of the banknote. Specifically, it is a light blue text and a light yellow-green area in the middle of the banknote.

Since the yellow-green area consists of a fluorescent dye comparable to that of Mexican banknote, the area of text (marked with A) was chosen for further analysis. Similar to previous banknotes, the area without fluorescent features (marked with B) was measured for the Russian banknote. Both measured areas have fluorescence around the peak at $410 \mathrm{~nm}$, as described for previous banknotes. However, in the case of Russian banknote, this fluorescence is not very evident due to the significant fluorescence intensity of area A. Area A has two distinct peaks: a narrow peak at $440 \mathrm{~nm}$ 
corresponding to medium blue colour and a wide peak at $460 \mathrm{~nm}$ corresponding to light blue colour. These two colours creates the resulting colour of the security feature visible under the UV lamp.
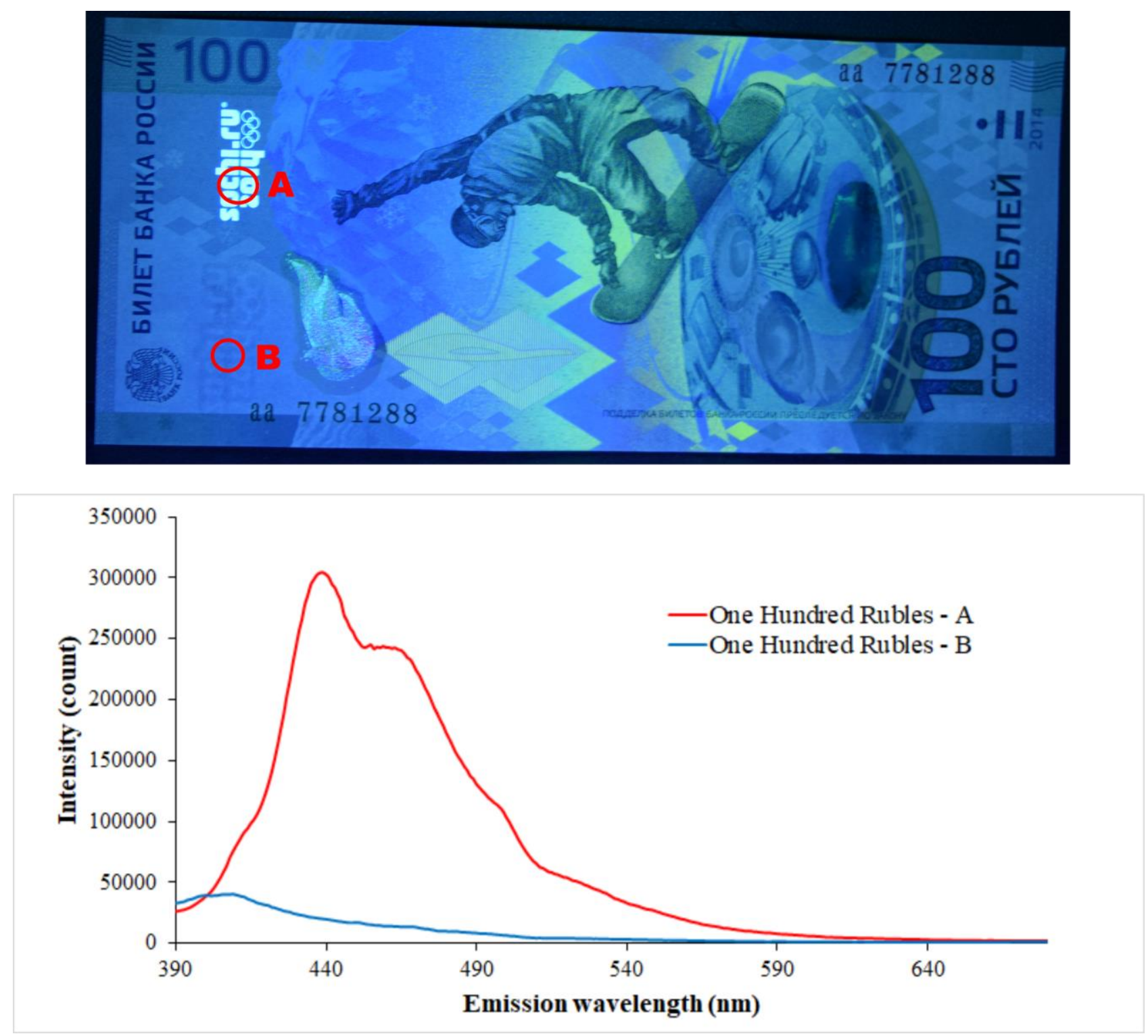

Fig. 5. Photograph of Russian banknote under a UV lamp and emission spectrum of this banknote

\section{Conclusion}

A UV lamp and steady-state fluorescence spectroscopy were used to analyse the properties of fluorescent dyes, which are used as security features for polymer banknotes. While the use of a UV lamp is common practice for detection of counterfeit polymer banknotes, the use of fluorescence spectroscopy for this purpose is new. The purpose was to determine the ability of steady-state fluorescence spectroscopy to analyse fluorescence properties of fluorescent dyes, which are used as security features for polymer banknotes. The given results indicate that all investigated banknotes have a similarly intense peak at $410 \mathrm{~nm}$, showing that these banknotes are made of the same polymer substrate to which optically brightening agents are added. Furthermore, all banknotes contain fluorescent dyes, which may be counterfeit; however, fluorescence properties of these dyes are difficult to imitate. Nevertheless, when measuring, it should be borne in mind that impurities on the banknote can fundamentally affect fluorescence intensity and that fluorescence spectroscopy provides no information about features, which have no fluorescence properties.

The overall results show that steady-state fluorescence spectroscopy can be used to detect counterfeit polymer banknotes. Moreover, information about the fluorescence properties of polymer banknotes was described. This information may be essential for the detection of counterfeits. One of the challenges for future research is to analyse other polymer banknotes to verify presented findings and compare original polymer banknotes with their counterfeits. 


\section{Acknowledgments}

This work was supported by the Internal Grant Agency of Tomas Bata University under the project No. IGA/FAI/2019/003.

\section{References}

[1] Davies, G. (2002). A History of Money: From Ancient Times to the Present Day. 3rd ed., with revisions. Cardiff: University of Wales Press, 2002. ISBN 07-083-1773-1.

[2] Jakob, J. (2019). Polymer banknotes, Bachelor thesis, Faculty of Applied Informatics, Tomas Bata University, Zlín, Czech Republic; Jakob, J. (2019). Polymerní bankovky. Bakalářská práce. Fakulta aplikované informatiky, Univerzita Tomáše Bati, Zlín.

[3] Morris, R. G., Copes, H. \& Perry-Mullis, K. (2002). Correlates of currency couterfeiting, Journal of Criminal Justice, Vol. 37, pp. 472-477. DOI: 10.1016/j.jcrimjus.2009.07.007

[4] Takalo, J., Timonen, J., Sampo, J., Rantala, M., Siltanen, S. \& Lassas, M. (2014). Using the fibre structure of paper to determine authenticity of the documents: Analysis of transmitted light images of stamps and banknotes. Forensic Science International, Vol. 244, pp. 252-258. DOI: 10.1016/j.forsciint.2014.09.002

[5] de Almeida, M. R., Correa, D. N., Rocha, W. F.C., Scafi, F. J.O., \& Poppi, R. J. (2012). Discrimination between authentic and counterfeit banknotes using Raman spectroscopy and PLS-DA with uncertainty estimation. Microchemical Journal, Vol. 109, pp. 170-177. DOI: 10.1016/j.microc.2012.03.006

[6] Kao, Y., Cheng, S., Cheng, Ch. \& Shiea, J. (2016). Depth profiling of inks in authentic and counterfeit banknotes by electrospray laser desorption ionization/mass spectrometry. Journal of Mass Spectrometry, Vol. 51, pp. 20-27. DOI: $10.1002 / \mathrm{jms} .3718$

[7] Xu, Y., Zhou, X. \& Shi, X. (2016). HPLC and HPLC/MS analysis of red ink on counterfeit 100-yuan notes. Forensic Science International, Vol. 259, pp. 47-52. DOI: 10.1016/j.forsciint.2015.11.018

[8] Guo, H., Yin, B., Zhang, J., Quan, Y. \& Shi, G. (2016). Forensic classification of counterfeit banknote paper by Xray fluorescence and multivariate statistical methods. Forensic Science International, Vol. 266, pp. e43-e47. DOI: 10.1016/j.forsciint.2016.06.008

[9] Solomon, D. H. \& Spurling, T. (2014). The plastic banknote: from concept to reality. Collingwood, VIC, Australia: CSIRO Publishing. ISBN 9780643094277.

[10] Guardian Fact Sheet (2013). CLL Secure, Craigieburn: Innovia Security. Available at: https://cclsecure.com/uploads/pdfs/Guardian_Fact_Sheet_Sep13.pdf

[11] Guinan, T., Kirkbride, P., Pigou, P. E., Ronci, M., Kobus, H. \& Voelcker, N. H. (2015). Surface-assisted laser desorption ionization mass spectrometry techniques for application in forensics. Mass Spectrometry Reviews, Vol. 34, pp. 627-640. DOI: 10.1002/mas.21431

[12] Skenderović Božičević, M., Gajović, A. \& Zjakić, I. (2012). Identifying a common origin of toner printed counterfeit banknotes by micro-Raman spectroscopy. Forensic Science International, Vol. 223, pp. 314-320. DOI: 10.1016/j.forsciint.2012.10.007

[13] Sonnex, E., Almond, M. J., Baum, J. V. \& Bond, J. W. (2014). Identification of forged Bank of England £20 banknotes using IR spectroscopy. Spectrochimica Acta Part A: Molecular and Biomolecular Spectroscopy, Vol. 118, pp. 1158-1163. DOI: 10.1016/j.saa.2013.09.115

[14] Vila, A., Ferrer, N., Mantecón, J., Bretón, D. \& García, J.F. (2006). Development of a fast and non-destructive procedure for characterizing and distinguishing original and fake euro notes. Analytica Chimica Acta, Vol. 559, Issue 2, pp. 257-263. DOI: 10.1016/j.aca.2005.11.084

[15] del Hoyo-Meléndez, J. M., Gondko, K., Mendys, A., Król, M., Klisińska-Kopacz, A., Sobczyk, J. \& JaworuckaDrath, A. (2016). A multi-technique approach for detecting and evaluating material inconsistencies in historical banknotes. Forensic Science International, Vol. 266, pp. 329-337. DOI: 10.1016/j.forsciint.2016.06.018

[16] Imperio, E., Calò, E., Valli, L. \& Giacane, G. (2015). Spectral investigations on $1000 £$ banknotes throughout Italian Republic. Vibrational Spectroscopy, Vol. 79, pp. 52-58, DOI: 10.1016/j.vibspec.2015.05.004

[17] Lim, H. \& Matham Murukeshan, V. (2017). Hyperspectral imaging of polymer banknotes for building and analysis of spectral library. Optics and Lasers in Engineering, Vol. 98, pp. 168-175. DOI: 10.1016/j.optlaseng.2017.06.022

[18] Petric Maretić, K., Bates., I. \& Modrić, D. (2014). Comparison of Colorimetric Values of Prints Made with Cyan Ink on Different Polymer Materials. Procedia Engineering, Vol. 69, pp. 1556-1561. DOI: 10.1016/j.proeng.2014.03.155. 